\title{
Article \\ Molecular Detection of Fluoroquinolone Resistance among Multidrug-, Extensively Drug-, and Pan-Drug-Resistant Campylobacter Species in Egypt
}

\author{
Ahmed M. Ammar ${ }^{1,+}$, Marwa I. Abd El-Hamid ${ }^{1,+} \oplus$, Rania M. S. El-Malt ${ }^{2}{ }^{\oplus}$, Doaa S. Azab ${ }^{3}$, Sarah Albogami ${ }^{4} \oplus^{(D}$, \\ Mohammad M. Al-Sanea ${ }^{5}\left(\mathbb{D}\right.$, Wafaa E. Soliman ${ }^{6,7} \mathbb{D}$, Mohammed M. Ghoneim ${ }^{8} \mathbb{D}$ and Mahmoud M. Bendary ${ }^{9, *} \mathbb{D}$ \\ 1 Department of Microbiology, Faculty of Veterinary Medicine, Zagazig University, Zagazig 44519, Egypt; \\ prof.ahmedammer_2000@yahoo.com (A.M.A.); mero_micro2006@yahoo.com (M.I.A.E.-H.) \\ 2 Animal Health Research Institute-Agriculture Research Center, Zagazig University, Zagazig 44516, Egypt; \\ raniaelmalt@yahoo.com \\ 3 Zagazig Veterinary Hospital, Zagazig University, Zagazig 44516, Egypt; gost_66@yahoo.com \\ 4 Department of Biotechnology, College of Science, Taif University, Taif 11099, Saudi Arabia; dr.sarah@tu.edu.sa \\ 5 Pharmaceutical Chemistry Department, College of Pharmacy, Jouf University, Sakaka 72341, Saudi Arabia; \\ mmalsanea@ju.edu.sa \\ 6 Department of Biomedical Sciences, College of Clinical Pharmacy, King Faisal University, \\ Al Ahsa 31982, Saudi Arabia; wafaaezz2006@yahoo.com \\ check for \\ updates \\ Citation: Ammar, A.M.; Abd \\ El-Hamid, M.I.; El-Malt, R.M.S.; Azab, \\ D.S.; Albogami, S.; Al-Sanea, M.M.; \\ Soliman, W.E.; Ghoneim, M.M.; \\ Bendary, M.M. Molecular Detection \\ 7 Microbiology and Immunology Department, Faculty of Pharmacy, Delta University for Science and \\ Technology, Gamasa 35712, Egypt \\ 8 Department of Pharmacy Practice, College of Pharmacy, Al Maarefa University, \\ Ad Diriyah 13713, Saudi Arabia; mghoneim@mcst.edu.sa \\ 9 Department of Microbiology and Immunology, Faculty of Pharmacy, Port Said University, \\ Port Said 42511, Egypt \\ * Correspondence: micro_bendary@yahoo.com or M.pendary@pharm.psu.edu.eg; Tel.: +20-12-2755-0629 \\ + These authors contributed equally to this work.
} of Fluoroquinolone Resistance among Multidrug-, Extensively Drug-, and Pan-Drug-Resistant Campylobacter Species in Egypt. Antibiotics 2021, 10, 1342. https://doi.org/10.3390/ antibiotics 10111342

Academic Editors: Seok Hoon Jeong and Eun-Jeong Yoon

Received: 12 October 2021

Accepted: 31 October 2021

Published: 3 November 2021

Publisher's Note: MDPI stays neutral with regard to jurisdictional claims in published maps and institutional affiliations.

Copyright: (c) 2021 by the authors. Licensee MDPI, Basel, Switzerland. This article is an open access article distributed under the terms and conditions of the Creative Commons Attribution (CC BY) license (https:// creativecommons.org/licenses/by/ $4.0 /)$.
Abstract: In recent times, resistant foodborne pathogens, especially of the Campylobacter species, have created several global crises. These crises have been compounded due to the evolution of multidrugresistant (MDR) bacterial pathogens and the emergence of extensively drug-resistant (XDR) and pandrug-resistant (PDR) strains. Therefore, this study aimed to investigate the development of resistance and the existence of both XDR and PDR among Campylobacter isolates. Moreover, we explored the use of the polymerase chain reaction-restriction fragment length polymorphism (PCR-RFLP) technique for the detection of fluoroquinolone (FQ)-resistant Campylobacter isolates. A total of 120 Campylobacter isolates were identified depending on both phenotypic and genotypic methods. Of note, cefoxitin and imipenem were the most effective drugs against the investigated Campylobacter isolates. Interestingly, the majority of our isolates (75\%) were MDR. Unfortunately, both XDR and PDR isolates were detected in our study with prevalence rates of $20.8 \%$ and $4.2 \%$, respectively. All FQ-resistant isolates with ciprofloxacin minimum inhibitory concentrations $\geq 4 \mu \mathrm{g} / \mathrm{mL}$ were confirmed by the genetic detection of gyrA chromosomal mutation via substitution of threonine at position 86 to isoleucine (Thr-86-to-Ile) using the PCR-RFLP technique. Herein, PCR-RFLP was a more practical and less expensive method used for the detection of FQ resistant isolates. In conclusion, we introduced a fast genetic method for the identification of FQ-resistant isolates to avoid treatment failure through the proper description of antimicrobials.

Keywords: Campylobacter species; PDR; FQ resistant; gyrA; PCR-RFLP

\section{Introduction}

Campylobacteriosis, caused by Campylobacter species (spp.), is a worldwide foodborne bacterial disease with zoonotic importance. Most of the human campylobacteriosis cases are caused by Campylobacter jejuni (C. jejuni) and the closely related Campylobacter coli 
(C. coli). Since 2005, campylobacteriosis is the most commonly reported gastrointestinal infection in humans in the European Union (EU) [1-3]. In developing countries, this disease is hyperendemic, especially in young children and infants $[4,5]$. The main source of human Campylobacter infection is the consumption of raw or uncooked meat, contaminated water and unpasteurized milk. Chicken is considered the main reservoir of Campylobacter infections because these bacteria are commensal in their intestinal tracts due to their high body temperature $[4,6,7]$.

Furthermore, cross-contamination with Campylobacter spp. is common during food processing and storing. The consumer's bad hygienic practices, such as cleaning raw chicken with water and using contaminated kitchen utensils, are considered the main causes of the wide spreading of campylobacteriosis. Additionally, poor hygiene especially during the defrosting and storing of chickens may increase the possibility of cross-contamination by this pathogen $[2,3,5]$.

Campylobacteriosis is a self-limiting disease with symptoms such as fever, nausea, vomiting, abdominal pains and watery or bloody diarrhea, but postinfection complications can occur such as Guillain-Barré syndrome, Miller Fisher syndrome and reactive arthritis in the case of immunocompromised patients [8,9]. In the majority of campylobacteriosis cases, antimicrobial treatment is not indicated, but in severe infections and immunocompromised persons, antimicrobials become of high importance [10]. Therefore, treatment failure in the severe cases may lead to death. Macrolides such as erythromycin and, fluoroquinolones (FQs) such as ciprofloxacin, are the drugs of choice in the treatment of infected cases [11]. Increasingly, a higher incidence of resistant Campylobacter spp. is detected worldwide due to the uncontrolled usage of antimicrobials in livestock breeding and through horizontal transmission in the poultry industry $[4,12]$. Campylobacter spp. have been described to be resistant to several antimicrobial classes including FQs, beta-lactams, tetracyclines and aminoglycosides, which leads to an increase in the number of infections with MDR Campylobacter strains [13].

Fluoroquinolones depend on the inhibition of the DNA gyrase, which is responsible for DNA repair, recombination, transcription and replication, and topoisomerase IV enzyme, leading to the generation of double breaks of DNA and cell death. On the other hand, two mechanisms explain the resistance to FQs; inactivation of the FQ targets and efflux of the drug. The inactivation process is mainly due to chromosomal point mutations in the quinolone-resistance-determining region (QRDR) of the gyr $A$ gene mostly by substitution of threonine at position 86 to isoleucine (Thr-86-to-lle); this alteration is always associated with high MIC values for FQs. Additionally, the resistance nodulation cell division superfamily efflux pump has been reported to play a role in the resistance to FQs $[12,14,15]$. The World Health Organization (WHO) announced in 2017 that fluoroquinolone-resistant Campylobacter spp. have been increasing all over the world, therefore alternative effective antibiotics must be found [16].

Nowadays, molecular techniques are of great importance in detecting the mutations in specific genes, which are responsible for the antimicrobial resistance. These techniques include denaturing gradient gel electrophoresis, DNA sequencing of the target gene, wholegenome sequencing, non-radioisotopic single-strand confirmatory polymorphism and a fluorogenic PCR assay as direct methods used for detection of the mutation, but they cannot be used as routine protocols for diagnosis as they are expensive and take a long time [12,15]. Therefore, alternative techniques such as PCR-based restriction fragment length polymorphism (PCR-RFLP) are more important as they are rapid, more practical and less expensive when they are used for the detection of mutations by the digestion of the PCR products using restriction enzyme and a specific restriction-site-modified primer. This technique was used as a diagnostic method for FQ-resistant Campylobacter spp. by determining the target mutations in QRDR of the gyrA gene [17]. There is a little information about the FQ resistance mechanism among Campylobacter species in Egypt [12,14]. Therefore, the current study aimed to get information about the occurrence and the resistance rates of Campylobacter isolates in Sharkia Governorate, Egypt. Additionally, we planned to provide 
the clinicians with a rapid detection method for FQ-resistant Campylobacter species using the PCR-RFLP technique, which will aid the physicians to make fast treatment decisions.

\section{Results}

\subsection{Prevalence of Campylobacter Species in Different Samples at Sharkia Governorate, Egypt}

According to the phenotypic identification, a total of 120 Campylobacter isolates (57.1\%) were obtained from 210 different samples at Sharkia Governorate, Egypt (Table 1). Campylobacter spp. were prevalent among human (85.7\%) and chicken (51.4\%) samples. Among chicken samples, Campylobacter isolates were more prevalent among cloacal swabs and liver $(88.6 \%$ each), while chicken franks and luncheon meat were Campylobacter negative (Table 1$)$.

Table 1. Prevalence of Campylobacter species in different samples at Sharkia Governorate, Egypt.

\begin{tabular}{cccc}
\hline Sample Type (Symbol, No.) & Total No. of Campylobacter * & \multicolumn{2}{c}{ No. of Campylobacter spp. (\%) * } \\
\cline { 2 - 4 } & Isolates (\%) & C. jejuni & C. coli \\
\hline Human stool swabs (H, 35) & $30(85.7)$ & $25(71.4)$ & $7(14.3)$ \\
Broiler chicken samples (C, 175) & $90(51.4)$ & $71(40.6)$ & $19(10.9)$ \\
Cloacal swabs (Ccs, 35) & $31(88.6)$ & $24(68.6)$ & $7(20)$ \\
Breast muscles (Cbm, 35) & $28(80)$ & $24(68.6)$ & $4(11.4)$ \\
Liver (Cl, 35) & $31(88.6)$ & 0 & 0 \\
Chicken franks (Cf, 35) & 0 & 0 & 0 \\
Chicken luncheon meats (Cln, 35) & 0 & $96(45.7)$ & $24(11.4)$ \\
Total (210) & $120(57.1)$ & & 0 \\
\hline
\end{tabular}

* The isolation rates were calculated concerning the total number of the examined samples.

Regarding the species level, C. jejuni was the predominant species (45.7\%), followed by C. coli $(11.4 \%)$. The highest isolation rates of $C$. jejuni isolates were observed in human stool swabs $(71.4 \%)$, followed by chicken cloacal swabs and breast muscle samples (68.6\% each). Meanwhile, the highest isolation rates of $C$. coli isolates were detected in the chicken liver $(22.9 \%)$, followed by human stool swabs (14.3\%) (Table 1). Furthermore, there were statistically significant differences $(p<0.001)$ in the prevalence of Campylobacter spp., C. jejuni and C. coli among different sample types.

\subsection{Antimicrobial Susceptibility Testing of Campylobacter Isolates}

\subsubsection{Antimicrobial Susceptibility Profiles of Campylobacter Species from Various Sources}

Analysis of the antimicrobial susceptibility of the recovered 120 Campylobacter isolates against the examined 24 antimicrobials showed that all the tested isolates were resistant to amoxycillin, ampicillin, cephalothin and erythromycin. Moreover, high resistance rates were detected against trimethoprim-sulfamethoxazole $(98.3 \%)$, followed by nalidixic acid (97.5\%), clarithromycin (96.7\%) and azithromycin and clindamycin (95\% each). On the other hand, the lowest resistance rates were observed against amikacin (39.2\%), imipenem $(40.8 \%)$ and cefoxitin (45.8\%) (Table 2$)$.

Regarding the species level, C. jejuni isolates were $100 \%$ resistant to nalidixic acid, trimethoprim-sulfamethoxazole and clarithromycin, while C. coli isolates were 100\% resistant to clindamycin. Additionally, our results showed higher resistance rates of C. jejuni than of C. coli isolates for the tested antimicrobials except for cefoxitin, cefoperazone, imipenem, doxycycline, azithromycin, tobramycin, amikacin, colistin and clindamycin (Figure 1). There were statistically significant differences in the resistance prevalence among $C$. jejuni and C. coli isolates against sulbactam-ampicillin, amoxycillinclavulanic acid, cefoxitin, ciprofloxacin, trimethoprim-sulfamethoxazole and chlorampheni$\operatorname{col}(p=0.01,0.023,0.011,0.016,0.039$ and 0.018 , respectively). Additionally, there were higher significant differences in the resistance prevalence among $C$. jejuni and $C$. coli isolates for cefepime, nalidixic acid, clarithromycin and gentamicin $(p=0.005,0.007,0.001$ and 0.003 , respectively). Meanwhile, there were no statistically significant differences in the 
resistance profiles among $C$. jejuni and $C$. coli isolates for the other tested antimicrobials $(p>0.05)$ (Figure 1).

Table 2. Antimicrobial resistance patterns of Campylobacter species isolated from different sources.

\begin{tabular}{|c|c|c|c|c|c|c|}
\hline \multirow{2}{*}{$\begin{array}{c}\text { Antimicrobial } \\
\text { Class }\end{array}$} & \multirow{2}{*}{$\begin{array}{c}\text { Antimicrobial } \\
\text { Agent }\end{array}$} & \multicolumn{2}{|c|}{$\begin{array}{c}\text { No. of } C . \text { jejuni Isolates (\%) } \\
(n=96)\end{array}$} & \multicolumn{2}{|c|}{$\begin{array}{l}\text { No. of C. coli Isolates (\%) } \\
\qquad(n=24)\end{array}$} & \multirow{2}{*}{$\begin{array}{l}\text { Total No. of } \\
\text { Campylobacter } \\
\text { Isolates (\%) } \\
(n=120)\end{array}$} \\
\hline & & Human (25) & Chicken (71) & Human (5) & Chicken (19) & \\
\hline \multirow{10}{*}{ Beta-lactams } & Amoxycillin & $25(100)$ & $71(100)$ & $5(100)$ & $19(100)$ & $120(100)$ \\
\hline & Ampicillin & $25(100)$ & $71(100)$ & $5(100)$ & $19(100)$ & $120(100)$ \\
\hline & $\begin{array}{l}\text { Sulbactam- } \\
\text { ampicillin }\end{array}$ & $15(60)$ & 47 (66.2) & $2(40)$ & $6(31.6)$ & $70(58.3)$ \\
\hline & $\begin{array}{l}\text { Amoxycillin- } \\
\text { clavulanic } \\
\text { acid }\end{array}$ & $23(92)$ & $66(93)$ & $2(40)$ & $16(84.2)$ & $107(89.2)$ \\
\hline & Cephalothin & $25(100)$ & $71(100)$ & $5(100)$ & $19(100)$ & $120(100)$ \\
\hline & Cefoxitin & $18(72)$ & $20(28.2)$ & $5(100)$ & $12(63.2)$ & $55(45.8)$ \\
\hline & Cefoperazone & $19(76)$ & $50(70.4)$ & $5(100)$ & 15 (78.9) & $89(74.2)$ \\
\hline & Cefepime & $25(100)$ & $60(84.5)$ & $5(100)$ & $10(52.6)$ & $100(83.3)$ \\
\hline & Imipenem & $6(24)$ & $32(45.1)$ & $2(40)$ & $9(47.4)$ & $49(40.8)$ \\
\hline & Aztreonam & $14(56)$ & $63(88.7)$ & $5(100)$ & $13(68.4)$ & 95 (79.2) \\
\hline \multirow{2}{*}{ Quinolones } & Nalidixic acid & $25(100)$ & $71(100)$ & $5(100)$ & $16(84.2)$ & $117(97.5)$ \\
\hline & Ciprofloxacin & $21(84)$ & $56(78.9)$ & $2(40)$ & $13(68.4)$ & $92(76.7)$ \\
\hline Sulfonamides & $\begin{array}{l}\text { Trimethoprim- } \\
\text { sulfamethoxazole }\end{array}$ & $25(100)$ & $71(100)$ & $3(60)$ & $19(100)$ & $118(98.3)$ \\
\hline Tetracyclines & Doxycycline & $25(100)$ & $54(76.1)$ & $3(60)$ & $19(100)$ & $101(84.2)$ \\
\hline \multirow{3}{*}{ Macrolides } & Erythromycin & $25(100)$ & $71(100)$ & $5(100)$ & $19(100)$ & $120(100)$ \\
\hline & Azithromycin & $25(100)$ & $66(93)$ & $5(100)$ & $18(94.7)$ & $114(95)$ \\
\hline & Clarithromycin & $25(100)$ & $71(100)$ & $3(60)$ & $17(89.5)$ & $116(96.7)$ \\
\hline \multirow{3}{*}{ Aminoglycosides } & Tobramycin & $15(60)$ & $47(66.2)$ & $5(100)$ & $13(68.4)$ & $80(66.7)$ \\
\hline & Gentamicin & $23(92)$ & $63(88.7)$ & $3(60)$ & $12(63.2)$ & $101(84.2)$ \\
\hline & Amikacin & $8(32)$ & $29(40.8)$ & $3(60)$ & $7(36.8)$ & $47(39.2)$ \\
\hline Oxazolidones & Linezolid & $25(100)$ & $51(71.8)$ & $3(60)$ & $15(78.9)$ & $94(78.3)$ \\
\hline Phenicols & Chloramphenicol & $23(92)$ & $59(83.1)$ & $2(40)$ & $13(68.4)$ & $97(80.8)$ \\
\hline Polypeptides & Colistin & $23(92)$ & $50(70.4)$ & $5(100)$ & $15(78.9)$ & $93(77.5)$ \\
\hline Lincosamide & Clindamycin & $25(100)$ & 65 (91.5) & $5(100)$ & $19(100)$ & $114(95)$ \\
\hline
\end{tabular}

According to the isolates' sources, higher resistance rates were observed among human Campylobacter isolates than the chicken ones for the investigated antimicrobials except for sulbactam-ampicillin, amoxycillin-clavulanic acid, imipenem, aztreonam, trimethoprimsulfamethoxazole, clarithromycin and amikacin (Figure 2). There were statistically significant differences in the resistance prevalence among human and chicken Campylobacter isolates against trimethoprim-sulfamethoxazole, linezolid and colistin $(p=0.041,0.038$ and 0.021 , respectively). Moreover, there were higher significant differences in the resistance prevalence among human and chicken Campylobacter isolates against cefepime, aztreonam ( $p=0.009$ and 0.008 , respectively) and cefoxitin $(p<0.001)$. Meanwhile, there were no statistically significant differences in the resistance profiles among human and chicken Campylobacter isolates for the other tested antimicrobials $(p>0.05)$ (Figure 2).

Interestingly, our results showed that among human samples, $C$. jejuni isolates were resistant to $9(16 \%)$ and $10(84 \%)$ antimicrobial classes, while $C$. coli isolates were resistant to $7(40 \%), 8(20 \%), 9(20 \%)$ and $10(20 \%)$ antimicrobial classes. Among chicken isolates, C. jejuni isolates were resistant to $7(12.7 \%), 8(19.7 \%), 9(31 \%)$ and $10(36.6 \%)$ antimicrobial classes, while $C$. coli isolates were resistant to $6(10.5 \%), 8$ and $9(15.8 \%$ each) and $10(57.9 \%)$ antimicrobial classes. In total, the resistance rates to seven, eight and nine antimicrobial classes were higher in chicken isolates $(10 \%, 18.9 \%$ and $27.8 \%$, respectively) than in the human ones $(6.7 \%, 3.3 \%$ and $16.7 \%$, respectively). Meanwhile, the resistance to 10 antimicrobial classes was higher in human isolates (73.3\%) than in the chicken ones (41.1\%) (Figure 3). 


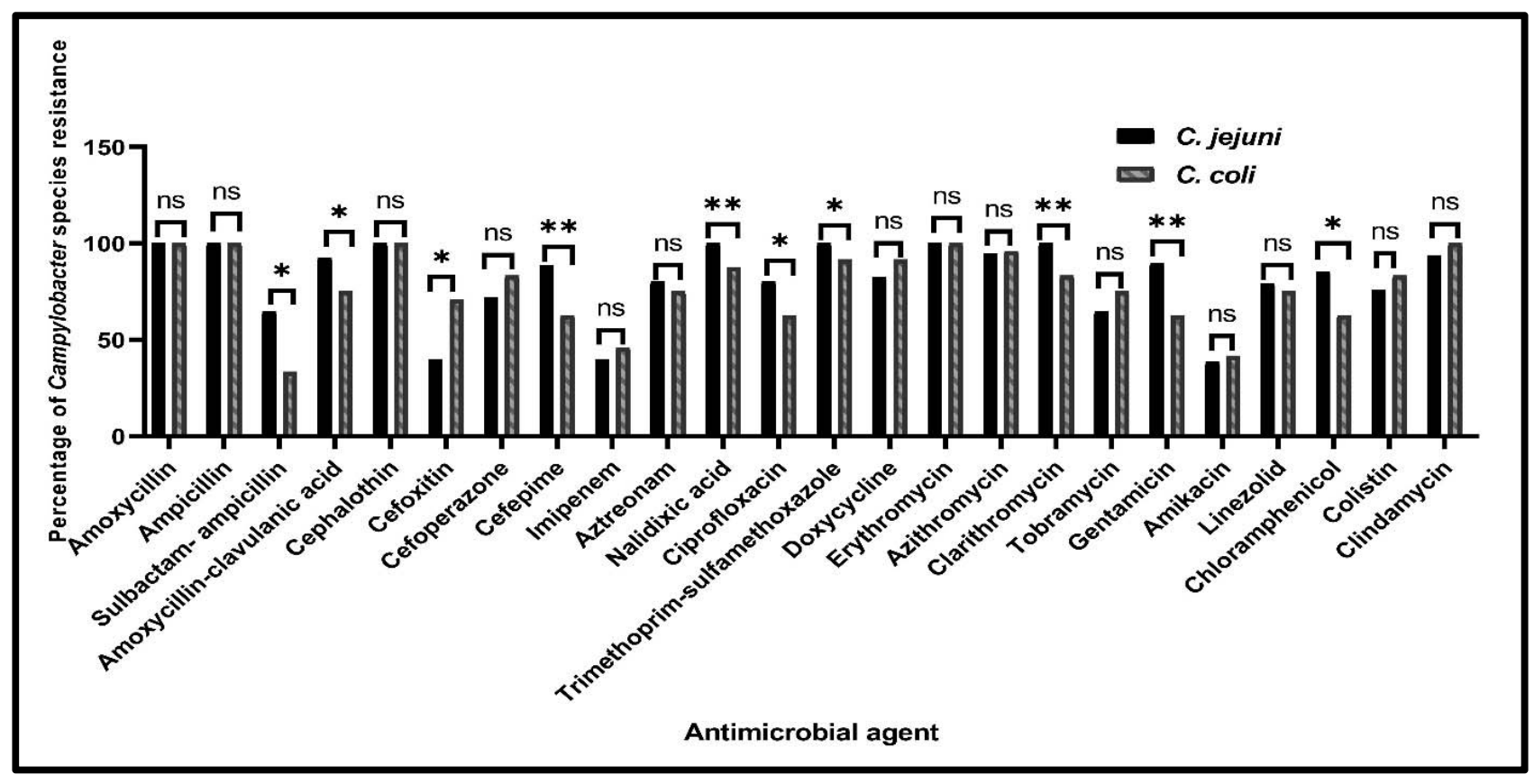

Figure 1. Prevalence of Campylobacter jejuni and Campylobacter coli resistance against 24 antimicrobial agents. ns: nonsignificant, ${ }^{*} p<0.05,{ }^{* *} p<0.01$.

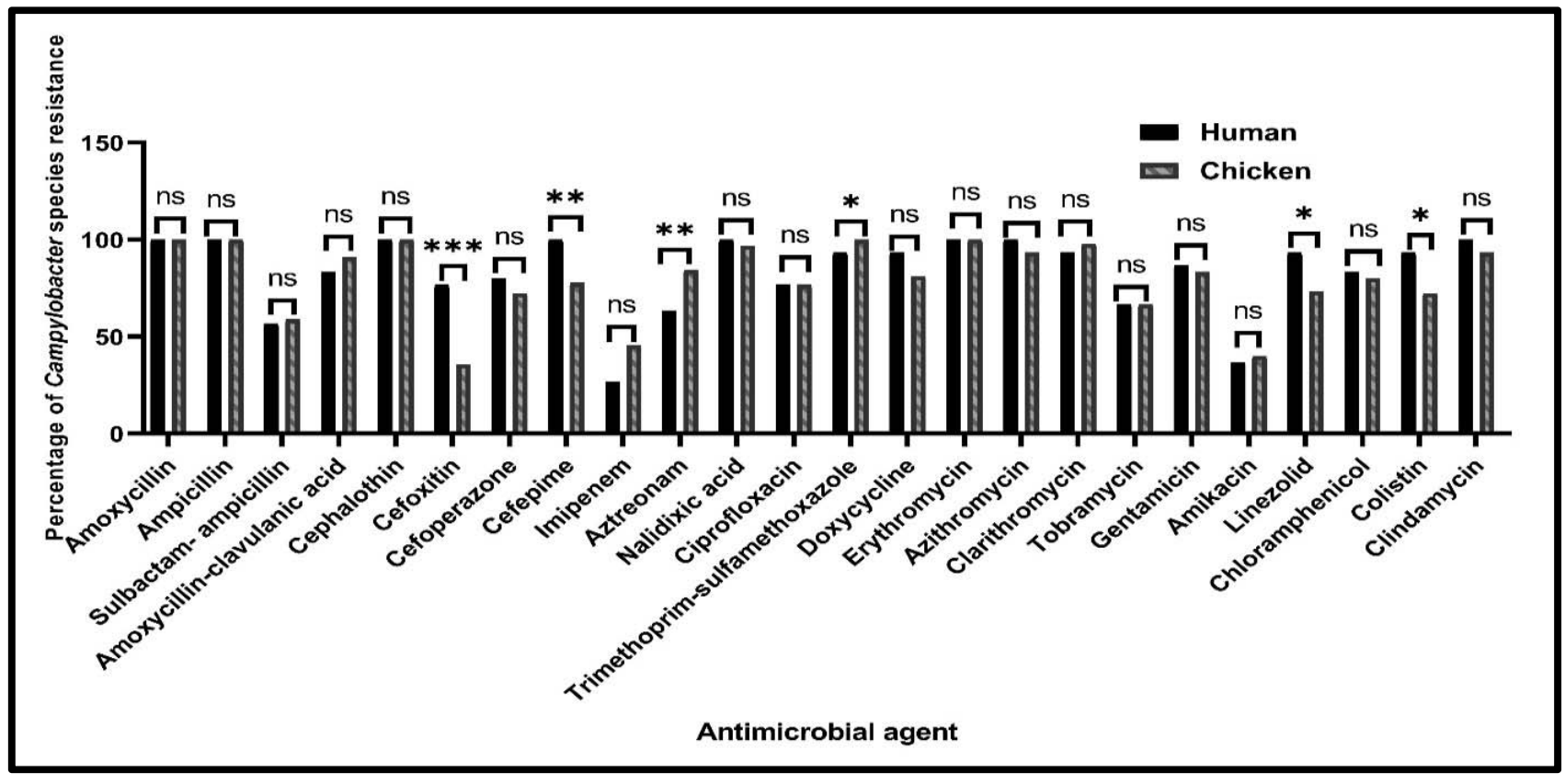

Figure 2. Prevalence of Campylobacter species resistance among human and chicken sources. ns: non-significant, ${ }^{*} p<0.05$, ${ }^{* *} p<0.01,{ }^{* * *} p<0.001$. 


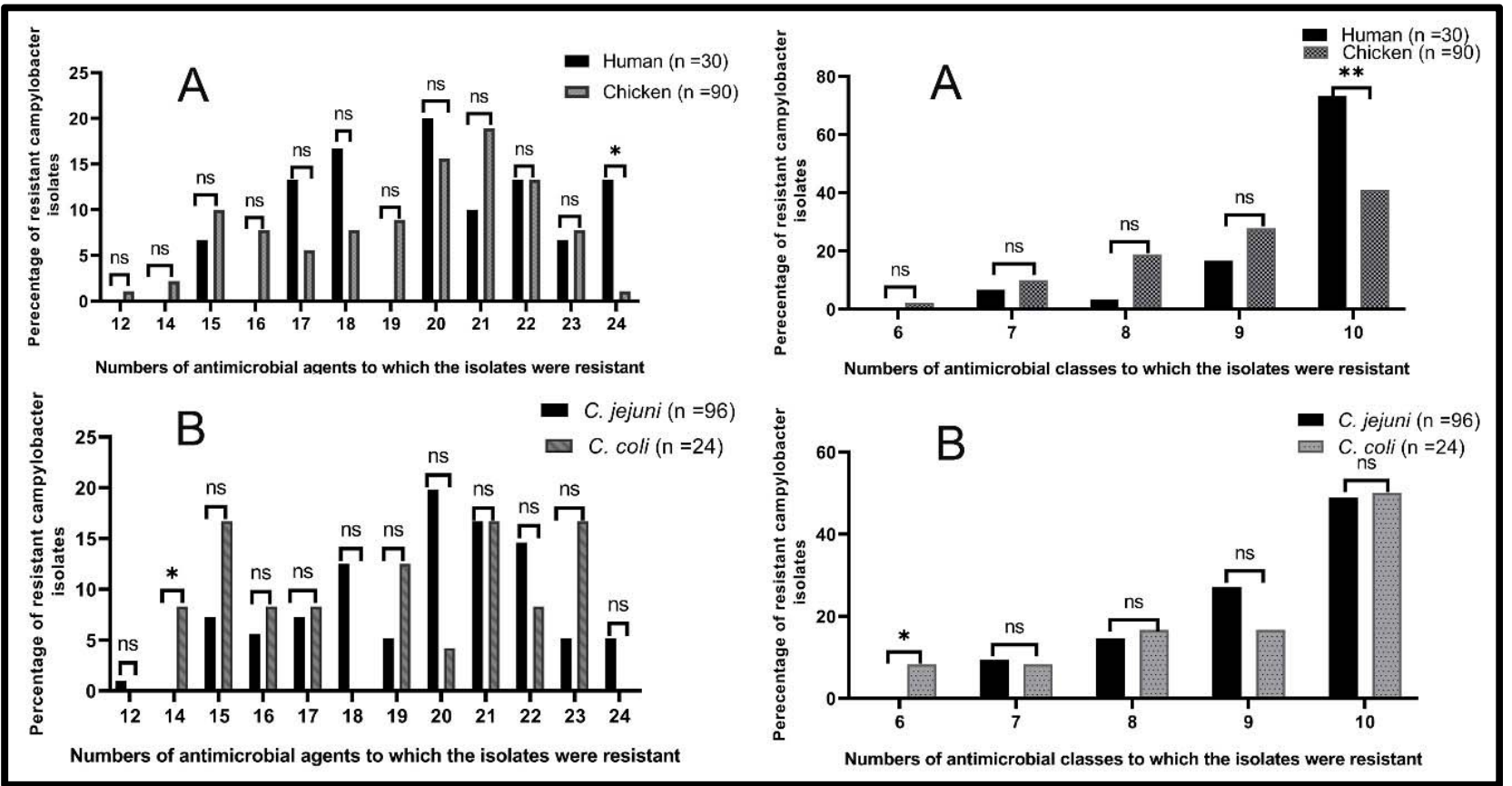

Figure 3. Antimicrobial resistance patterns of human and chicken Campylobacter isolates (A) and C. jejuni and C. coli (B). $n$ : number, ns: non-significant, ${ }^{*} p<0.05,{ }^{* *} p<0.01$.

Of note, it was found that 90 Campylobacter isolates $(75 \%)$ were MDR, while 25 isolates (20.8\%) were recognized as XDR; 6 (20\%) and 19 (21.1\%) were obtained from human and chicken samples, respectively. Finally, five Campylobacter isolates (4.2\%) were classified as PDR; four $(13.3 \%)$ and one $(1.1 \%)$ were obtained from human and chicken origins, respectively. Determining the MAR indices showed that all tested human isolates had an index of 0.63 or greater, while chicken isolates had an index of 0.50 or greater, which indicate high-risk sources of contamination, where antimicrobial agents are usually utilized (Table 3). Out of 30 Campylobacter isolates that had MAR indices greater than 0.9 (resistance to 22 or more antimicrobials), $20(22.2 \%)$ and 10 (33.3\%) were isolated from chickens and human samples, respectively (Table 3 ). There were statistically significant differences in the resistance patterns to 24 antimicrobials and 10 antimicrobial classes among Campylobacter isolates from chicken and human origins ( $p=0.014$ and 0.003 , respectively) (Figure 3A). Moreover, there were statistically significant differences in the resistance patterns to 14 antimicrobials and 6 antimicrobial classes among C. jejuni and C. coli isolates $(p=0.039$ and 0.039, respectively) (Figure 3B).

\subsubsection{The Minimum Inhibitory Concentrations of Ciprofloxacin against Campylobacter Isolates}

Thirty-eight ciprofloxacin-resistant Campylobacter isolates that were resistant to 21 or more antimicrobials were tested against ciprofloxacin antibiotic by the broth microdilution method for the determination of its minimum inhibitory concentrations (MICs). Those isolates were recovered from human (13) and chicken (25) sources. The 25 chicken isolates were obtained from the chicken liver (11) and cloacal swabs and breast meat (7 each) samples. Interestingly, all the 38 tested isolates were 100\% resistant to ciprofloxacin (MIC $\geq 4 \mu \mathrm{g} / \mathrm{mL}$ ) (Table 4 ) and these results were $100 \%$ correlated with those of the disc diffusion method. Additionally, the minimum bactericidal concentration (MBC) values of ciprofloxacin ranged from 8 to $\geq 256 \mu \mathrm{g} / \mathrm{mL}$. 
Table 3. Multiple antibiotic resistance indices of Campylobacter species isolated from different sources.

\begin{tabular}{|c|c|c|c|c|c|c|c|c|}
\hline \multirow{3}{*}{ MAR Index } & \multirow{3}{*}{$\begin{array}{l}\text { No. of Antimi- } \\
\text { crobials to } \\
\text { Which the } \\
\text { Isolates Were } \\
\text { Resistant }\end{array}$} & \multirow{3}{*}{ No. of AMC } & \multicolumn{4}{|c|}{$\begin{array}{c}\text { No. of Resistant Campylobacter Isolates from } \\
\text { Different Sources (\%) }\end{array}$} & \multirow{3}{*}{ Total (120) } & \multirow{3}{*}{$\begin{array}{c}\text { Character of } \\
\text { Resistant } \\
\text { Strains }\end{array}$} \\
\hline & & & \multicolumn{2}{|c|}{ Human (30) } & \multicolumn{2}{|c|}{ Chicken (90) } & & \\
\hline & & & C. jejuni (25) & C. coli (5) & C. jejuni (71) & C. coli (19) & & \\
\hline 0.50 & 12 & 7 & - & - & $1(1.4)$ & - & $1(0.8)$ & \multirow{20}{*}{ MDR } \\
\hline 0.58 & 14 & 6 & - & - & - & $2(10.5)$ & $2(1.7)$ & \\
\hline \multirow{2}{*}{0.63} & \multirow{2}{*}{15} & 7 & - & $2(40)$ & $5(7.1)$ & - & $7(5.8)$ & \\
\hline & & 8 & - & - & $2(2.8)$ & $2(10.5)$ & $4(3.3)$ & \\
\hline \multirow{3}{*}{0.67} & \multirow{3}{*}{16} & 8 & - & - & $5(7)$ & - & $5(4.2)$ & \\
\hline & & 10 & - & - & - & $2(10.5)$ & $2(1.7)$ & \\
\hline & & 7 & - & - & $3(4.2)$ & - & $3(2.5)$ & \\
\hline \multirow{4}{*}{0.71} & \multirow{3}{*}{17} & 8 & - & $1(20)$ & - & - & $1(0.8)$ & \\
\hline & & 9 & - & - & $1(1.4)$ & $1(5.3)$ & $2(1.7)$ & \\
\hline & & 10 & $3(12)$ & - & - & - & $3(2.5)$ & \\
\hline & \multirow{4}{*}{18} & 8 & - & - & $2(2.8)$ & - & $2(1.7)$ & \\
\hline \multirow[t]{3}{*}{0.75} & & 9 & $2(8)$ & - & $3(4.2)$ & - & $5(4.2)$ & \\
\hline & & 10 & $3(12)$ & - & $2(2.8)$ & - & $5(4.2)$ & \\
\hline & & 8 & - & - & $1(1.4)$ & $1(5.3)$ & $2(1.7)$ & \\
\hline \multirow[t]{2}{*}{0.79} & \multirow[t]{2}{*}{19} & 9 & - & - & $1(1.4)$ & $1(5.3)$ & $2(1.7)$ & \\
\hline & & 10 & - & - & $3(4.2)$ & $1(5.3)$ & $4(3.3)$ & \\
\hline \multirow[b]{2}{*}{0.83} & \multirow[b]{2}{*}{20} & 9 & $2(8)$ & - & $4(5.6)$ & - & $6(5)$ & \\
\hline & & 10 & $4(16)$ & - & $9(12.7)$ & $1(5.3)$ & $14(11.7)$ & \\
\hline \multirow{2}{*}{0.88} & \multirow{2}{*}{21} & 9 & - & - & $13(18.3)$ & $1(5.3)$ & $14(11.7)$ & \\
\hline & & 10 & $3(12)$ & - & - & 3 (15.8) & $6(5)$ & \\
\hline \multirow{2}{*}{0.92} & \multirow{2}{*}{22} & 8 & - & - & $4(5.6)$ & - & $4(3.3)$ & \multirow{4}{*}{ XDR } \\
\hline & & 10 & $4(16)$ & - & $6(8.5)$ & 2 (10.5) & $12(10)$ & \\
\hline \multirow{2}{*}{0.96} & \multirow{2}{*}{23} & 9 & - & $1(20)$ & - & - & $1(0.8)$ & \\
\hline & & 10 & - & $1(20)$ & $5(7)$ & 2 (10.5) & $8(6.7)$ & \\
\hline 1 & 24 & 10 & $4(16)$ & - & $1(1.4)$ & - & $5(4.2)$ & PDR \\
\hline
\end{tabular}

MAR: multiple antibiotic resistance, AMC: antimicrobial classes, MDR: multidrug resistant, XDR: extensively drug resistant, PDR: pan drug resistant.

Table 4. Minimal inhibitory concentrations of ciprofloxacin against Campylobacter isolates from different sources.

\begin{tabular}{|c|c|c|c|c|c|c|c|c|c|c|}
\hline \multirow{2}{*}{ Isolates Source } & \multirow{2}{*}{$\begin{array}{l}\text { Campylobacter } \\
\text { Species }\end{array}$} & \multicolumn{7}{|c|}{ No. of Campylobacter Isolates Showing MIC Values of Ciprofloxacin $(\mu \mathrm{g} / \mathrm{mL})$ * } & \multirow{2}{*}{$\mathrm{MIC}_{50}$} & \multirow{2}{*}{$\mathrm{MIC}_{90}$} \\
\hline & & 4 & 8 & 16 & 32 & 64 & 128 & $\geq 256$ & & \\
\hline \multirow{2}{*}{ Chicken (25) } & C. jejuni (18) & 2 & 5 & 5 & 1 & 2 & 2 & 1 & 16 & 128 \\
\hline & C. $\operatorname{coli}(7)$ & 2 & 3 & 2 & - & - & - & - & 8 & 16 \\
\hline \multirow{2}{*}{ Human (13) } & C. jejuni (11) & 2 & 2 & 3 & - & - & - & 4 & 16 & 256 \\
\hline & C. $\operatorname{coli}(2)$ & - & - & 1 & - & 1 & - & - & 16 & 64 \\
\hline \multicolumn{2}{|c|}{ Total (38) } & 6 & 10 & 11 & 1 & 3 & 2 & 5 & 16 & 256 \\
\hline
\end{tabular}

$*$ All isolates were resistant to ciprofloxacin $(\mathrm{MIC} \geq 4 \mu \mathrm{g} / \mathrm{mL}), \mathrm{MIC}:$ minimum inhibitory concentration, $\mathrm{MIC}_{50}=(n \times 0.5), \mathrm{MIC}_{90}=(n \times 0.9)$.

\subsection{Molecular Grouping of Campylobacter Isolates from Different Sources}

All the 38 screened Campylobacter isolates $(100 \%)$ were identified as genus Campylobacter (Figure 4). Moreover, 29 isolates (76.3\%) were positive for mapA gene and confirmed to be $C$. jejuni (Figure 5A), while the remaining 9 isolates $(23.7 \%)$ were positive for the ceuE gene and confirmed to be $C$. coli (Figure $5 \mathrm{~B}$ ). These results were $100 \%$ correlated with those of the conventional identification methods. Of the 29 C. jejuni isolates, $11(37.9 \%)$ were obtained from human and 18 (62.1\%) from chicken sources. Moreover, nine C. coli isolates were obtained from seven chicken $(77.8 \%)$ and two human $(22.2 \%)$ samples. There were statistically significant differences in the prevalence of $C$. jejuni and $C$. coli isolates among human stool swabs and chicken breast meat samples ( $p=0.001$ and 0.029 , respectively). Meanwhile, there were no statistically significant differences in the prevalence of $C$. jejuni and C. coli isolates among chicken liver and cloacal swabs samples ( $p=0.395$ and 0.286 , respectively) (Figure 6). 


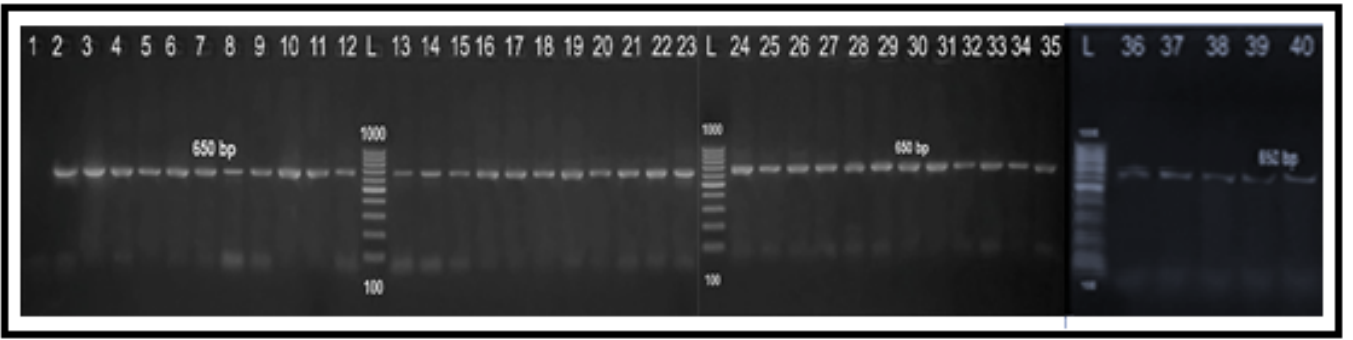

Figure 4. Agarose gel electrophoresis showing typical amplification products of $23 S \mathrm{RNA}$ gene for confirmation of genus Campylobacter. Lane L: 100 bp DNA ladder "Marker", lane 1: negative control (PCR grade water), lane 2: positive control (C. jejuni NCTC11322), lanes 3-15: positive Campylobacter isolates from human stool swabs and lanes 16-40: positive Campylobacter isolates from chicken samples.

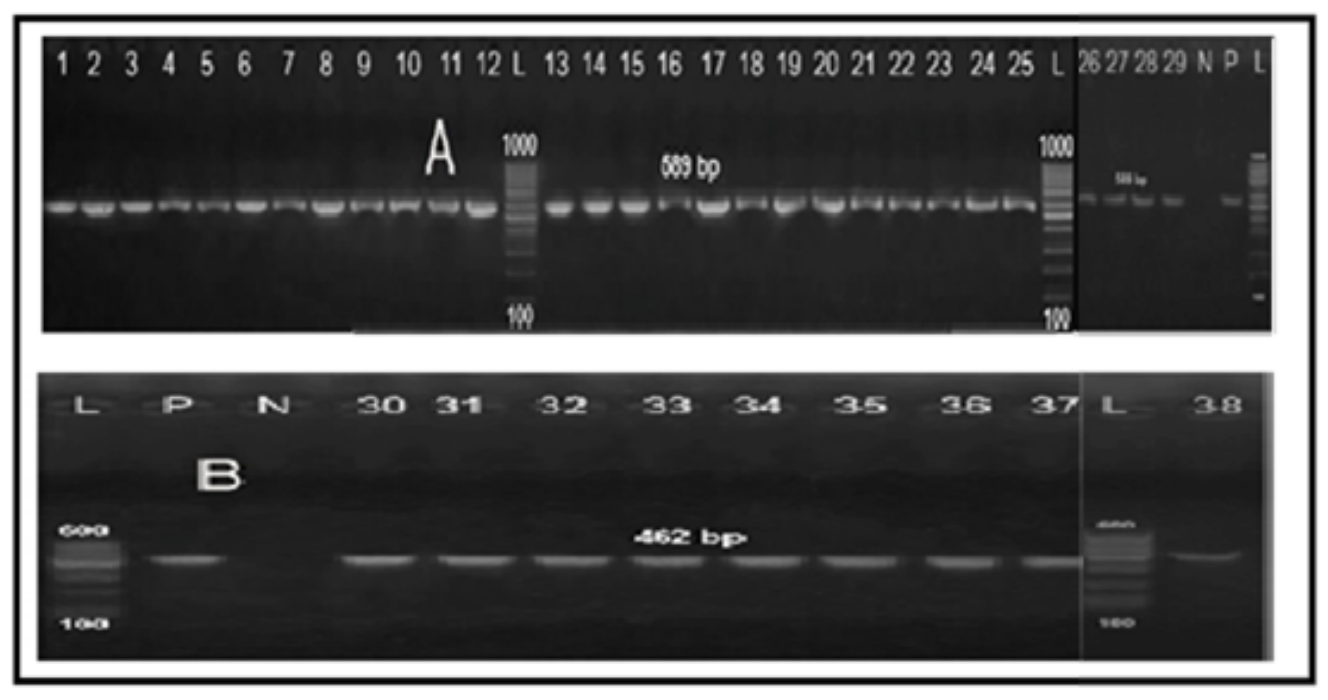

Figure 5. PCR amplification products of mapA gene specific for C. jejuni (A) and ceuE gene specific for C. coli (B). Lanes 1-11: C. jejuni from human origin, lanes 12-29: C. jejuni from chicken samples, lanes 30-31: C. coli from human samples, lane 32-38: C. coli from chicken origin, lane L: 100 bp DNA ladder "Marker", lane P: positive controls (C. jejuni NCTC11322 and C. coli NCTC11366), lane N: negative control (PCR-grade water).

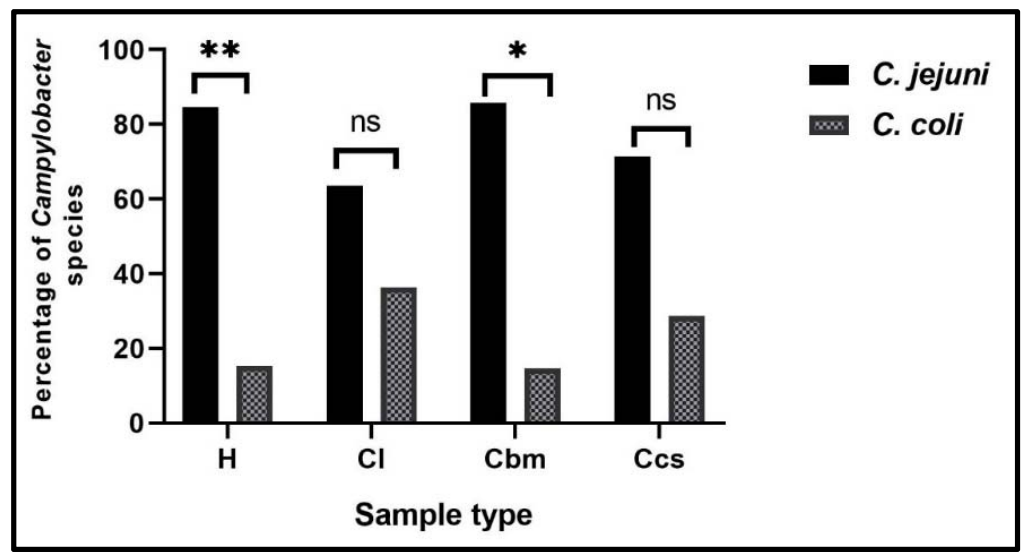

Figure 6. Prevalence of molecularly identified Campylobacter species in different samples. H: human stool swabs, $\mathrm{Cl}$ : chicken liver, $\mathrm{Cbm}$ : chicken breast meat, $\mathrm{Ccs}$ : chicken cloacal swabs, ns: nonsignificant, ${ }^{*} p<0.05,{ }^{* *} p<0.01$. 


\subsection{Determination of Fluoroquinolone Resistance by PCR-RFLP Technique}

All the 38 tested Campylobacter isolates had the same RFLP fragments (179 bp) (Figure 7), which suggested having a chromosomal point mutation in the QRDR of the gyrA gene by substitution of threonine amino acid at position 86 to isoleucine (Thr-86-to-Ile). Additionally, there was a $100 \%$ correlation between the ciprofloxacin MIC values and the PCR-RFLP results.

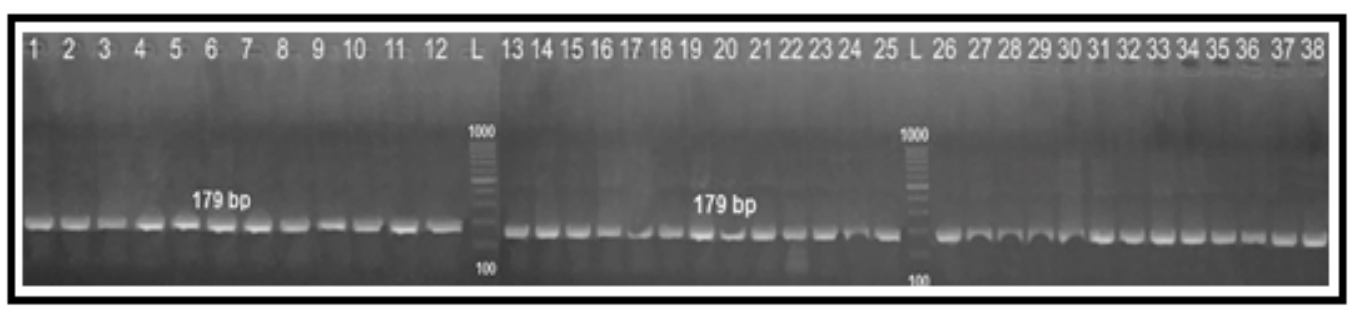

Figure 7. PCR-restriction fragment length polymorphism patterns obtained after digestion of gyrA PCR products with FastDigest RsaI enzyme. Lane L: 100 bp DNA ladder and lanes 1-38: PCR-RFLP fragments obtained for Campylobacter species isolated from human and chicken samples.

\section{Discussion}

It was announced that several worldwide crises were developed due to the wide spreading of resistant fungi [18] and bacteria such as MRSA, VRSA and Klebsiella spp., in addition to zoonotic foodborne pathogens including Campylobacter spp., Salmonella enteritidis and Salmonella typhimurium [10,19-26]. The increasing antimicrobial resistance of Campylobacter spp., especially to FQs, macrolides and tetracyclines, is of great importance to human health worldwide. Our results revealed a high prevalence of Campylobacter spp. (57.1\%) in samples recovered from chicken and human origins at Sharkia Governorate, Egypt. This is partially similar to a previous study carried out in Poland (54.4\%) [27], but the levels were higher than those obtained in previous studies carried out in Egypt; 32.8\% [10], $27.3 \%$ [28] and 7.6\% [29]. Herein, Campylobacter spp. were more prevalent among human samples, followed by chicken ones, which was in contrast with previous studies conducted in Egypt, where Campylobacter spp. were more prevalent among chicken samples, followed by human ones $[29,30]$. Among our chicken samples, Campylobacter spp. were more prevalent among cloacal swabs and liver $(88.6 \%$ each), which is higher than prevalences reported in a previous study carried out in Egypt (54.3\% and 34.1\%, respectively) [10]. In the current study, chicken franks and luncheon meats were Campylobacter negative ( $0 \%$ each), which is in complete agreement with a previous study conducted in Egypt [31]. Of note, the most common Campylobacter spp. was C. jejuni (45.7\%), which is in complete agreement with the results of other studies carried out in Tunisia (68.9\%) [32] and South Korea (77.6\%) [33]. Generally, the variations in the prevalence of Campylobacter spp. among various studies could be due to the type of the tested samples, hygienic measures, isolation and identification methods, environmental conditions and the geographical location [34].

Unsurprisingly, there is a variation in the antimicrobial resistance among and within different countries, which strongly correlated with the type of prescribed drugs alongside the variation in guidelines for the use of antimicrobial drugs. In this context, the high levels of ciprofloxacin and doxycycline resistance rates detected among our tested isolates ( $76.7 \%$ and $84.2 \%$, respectively) were lower than those detected in a previous study carried out in Tunisia (99.2\% and 100\%, respectively) [35]. Alarmingly, there has been a global warning concerning the evolution of MDR strains; however, concrete steps are being taken against the spread of both XDR and PDR strains. Herein, 75\%, 20.8\% and $4.2 \%$ of the tested Campylobacter isolates were recognized as MDR, XDR and PDR, respectively. This is consistent with the results of a previous study conducted in Egypt, where the above-mentioned resistance criteria were observed among $28.5 \%, 69 \%$ and $2.5 \%$ of the tested isolates, respectively [31]. In the current study, all Campylobacter isolates had MAR 
indices of 0.5 or greater. These results were higher than those recorded in a previous study conducted in South Africa, where MAR indices of the tested isolates were 0.2 or lower [36]. The high resistance rates of Campylobacter isolates in developing countries could be due to the uncontrolled usage of antimicrobials in veterinary medicine as growth promoters and in human and animal treatments without any prescription. Additionally, the high resistance rates observed in the present study to erythromycin, ciprofloxacin and doxycycline are alarming as these antibiotics are the drugs of choice used for the treatment of human campylobacteriosis, which causes a fundamental problem, where antibiotic treatment become limited. Therefore, antimicrobial usage must be controlled in animals and humans. Additionally, there is an urgent need for the wide application of alternative drugs from medicinal plants $[37,38]$ or drug repurposing [39].

One of the best drugs available for treating human campylobacteriosis is FQ antibiotics. Many physicians describe FQs as a first-line therapy $[11,12,15,17]$. Unfortunately, there is widespread FQ resistance due to mutations in the gyrase gene [15]. Clinically, it is very important to find a rapid genetic method for the detection of gyrase gene mutations instead of sequencing methods. In the present study, the PCR-RFLP results for all examined isolates revealed that they all had the same fragment pattern (179 bp), which confirmed the resistance to ciprofloxacin and suggested the presence of a chromosomal point mutation in the QRDR of the gyrA gene by substitution of threonine amino acid at position 86 to isoleucine (Thr-86-to-Ile). Accordingly, there was a strong direct correlation between the MIC values of ciprofloxacin and the PCR-RFLP results. This result was in complete agreement with a previous study conducted in Brazil [15], which can help in controlling the FQ resistance and allow the proper usage of antibiotics.

\section{Materials and Methods}

\subsection{Ethical Statement}

The sole aim of the specimen collection in this study was to care for patients and to perform antimicrobial susceptibility testing for proper diagnosis and treatment. Therefore, it was not necessary to take the ethical approval, but prior to starting the study, the participants provided informed consent.

\subsection{Sample Collection}

This study was carried out between March 2017 and September 2018 (18 months) at Zagazig city, Sharkia Governorate, Egypt. A total of 210 samples were collected from chicken $(n=175)$ and human $(n=35)$ sources. Ten samples from chickens of 6 weeks of age were collected per month from multiple retail outlets $(n=16,11$ samples from each outlet) including cloacal swabs, breast muscles, liver, chicken franks and chicken luncheon meats ( $n=35$ each), while human stool samples were obtained as swabs from diseased children with diarrhea from private laboratories at Zagazig city. Cloacal and stool swabs were transferred directly into a sterile tube containing $9 \mathrm{~mL}$ of Bolton broth with Bolton broth selective supplement (Oxoid, UK) with $20 \mathrm{~mm}$ space lift in the tube to achieve microaerophilic conditions, while other samples were transferred into ice boxes for laboratory isolation and identification of Campylobacter spp.

\subsection{Isolation and Identification of Campylobacter Species}

Isolation of Campylobacter spp. was achieved according to the International Standards Organization (ISO) guidelines [40]. Briefly, the enrichment broth containing samples was incubated for $48 \mathrm{~h}$ at $42{ }^{\circ} \mathrm{C}$ in darkness under microaerophilic conditions $\left(5 \% \mathrm{O}_{2}\right.$, $10 \% \mathrm{CO}_{2}$ and $85 \% \mathrm{~N}_{2}$ ) using CampyGen sachets (Oxoid, Cheshire, UK) and anaerobic jar (Oxoid, Cheshire, UK). After that, $10 \mu \mathrm{L}$ of the enrichment broth was streaked onto the surface of the selective modified charcoal cefoperazone deoxycholate agar (mCCDA) plates with CCDA selective supplement (Oxoid, Cheshire, UK), and the plates were incubated for $48 \mathrm{~h}$ at $42{ }^{\circ} \mathrm{C}$ in darkness under microaerophilic conditions. For more purification, suspicious colonies were cultivated onto blood agar (Oxoid, Cheshire, UK) supplemented 
with $5 \%$ sterile defibrinated sheep blood, and the plates were incubated for $48 \mathrm{~h}$ under microaerophilic conditions. The Campylobacter isolates were presumptively confirmed via cultural characteristics on mCCDA, Gram's staining, motility, some biochemical tests such as catalase, oxidase and indoxyl acetate and sodium hippurate hydrolysis tests and finally susceptibility to nalidixic and cephalothin.

\subsection{Antimicrobial Susceptibility Testing}

\subsubsection{Disc Diffusion Method}

Kirby-Bauer disc diffusion method [41] was used to determine the susceptibility of all Campylobacter isolates to 24 antimicrobials belonging to 10 different antimicrobial classes that were regularly used in human and veterinary medicine in Egypt using the following antimicrobial discs (Oxoid, Cheshire, UK); amoxycillin (AX, $25 \mu \mathrm{g}$ ), ampicillin (AM, $10 \mu \mathrm{g}$ ), sulbactam-ampicillin (SAM, $10+10 \mu \mathrm{g}$ ), amoxycillin-clavulanic acid (AMC, $20+10 \mu \mathrm{g})$, cephalothin (KF, $30 \mu \mathrm{g})$, cefoxitin (FOX, $30 \mu \mathrm{g})$, cefoperazone (CEP, $75 \mu \mathrm{g}$ ), cefepime (FEP, $30 \mu \mathrm{g}$ ), imipenem (IMP, $10 \mu \mathrm{g}$ ), aztreonam (ATM, $30 \mu \mathrm{g}$ ), nalidixic acid (NA, $30 \mu \mathrm{g}$ ), ciprofloxacin (CIP, $5 \mu \mathrm{g}$ ), trimethoprim-sulfamethoxazole (SXT, $23.75+1.25 \mu \mathrm{g}$ ), doxycycline (DO, $30 \mu \mathrm{g})$, erythromycin (E, $15 \mu \mathrm{g})$, azithromycin (AZM, $30 \mu \mathrm{g})$, clarithromycin $(\mathrm{CLR}, 15 \mu \mathrm{g})$, tobramycin (TOB, $10 \mu \mathrm{g})$, gentamicin $(\mathrm{CN}, 10 \mu \mathrm{g})$, amikacin $(\mathrm{AK}, 30 \mu \mathrm{g})$, linezolid (LNZ, $30 \mu \mathrm{g})$, chloramphenicol (C, $30 \mu \mathrm{g})$, colistin (CT, $10 \mu \mathrm{g})$ and clindamycin $(\mathrm{DA}, 2 \mu \mathrm{g})$. Few (3-10) colonies were added to a tube containing $5 \mathrm{~mL}$ of sterile physiological saline $(0.9 \%)$ to make the bacterial suspension, which was compared with $0.5 \mathrm{McFarland}$ standard solution. After that, the prepared suspension was streaked on the surface of Mueller-Hinton agar (Oxoid, Cheshire, UK) supplemented with 5\% sterile defibrinated sheep blood and then the discs were placed into the plates, which were inverted and incubated at $42{ }^{\circ} \mathrm{C}$ for $24-48 \mathrm{~h}$ in darkness under microaerophilic conditions. The degree of susceptibility was determined by measuring the visible inhibition zones, and the results were interpreted according to the breakpoints of the Clinical Laboratory Standard Institute (CLSI) to categorize the antimicrobial agents into resistant, intermediate or susceptible [42,43].

The MDR Campylobacter isolates were defined as isolates that showed resistance to one or more antimicrobials in at least three different classes, while the isolates resistant to one agent from all antimicrobial categories with the exception of one or two categories were termed as extensively drug resistant (XDR). Meanwhile, the isolates resistant to all agents in all antimicrobial categories were described as pan drug resistant (PDR) [44]. Finally, the multiple antibiotic resistance (MAR) indices of the isolates were determined by the following equation: number of antibiotics to which the isolates were resistant/the total number of antibiotics used [45].

\subsubsection{Broth Microdilution Method for Determining Ciprofloxacin Minimal Inhibitory Concentrations}

The double-fold broth microdilution method was used to determine the MIC values of ciprofloxacin (EPPI, Cairo, Egypt) using Mueller-Hinton broth (Oxoid, Cheshire, UK) as per the CLSI guidelines [42]. Double-fold serial dilution of ciprofloxacin was done in the 96-well microtiter plates (Techno Plastic Products, Trasadingen, Switzerland) with the initial concentration of $256 \mu \mathrm{g} / \mathrm{mL}$. The microtiter plates were incubated at $42{ }^{\circ} \mathrm{C}$ in darkness under microaerobic conditions for $48 \mathrm{~h}$. The MIC of ciprofloxacin was defined as the lowest concentration that prevented the visible growth of Campylobacter isolates after $48 \mathrm{~h}$ incubation [46], and the MBC of ciprofloxacin was defined as the lowest concentration that killed $99.9 \%$ of the bacterial population after $48 \mathrm{~h}$ incubation [47]. Positive control was included through preparing the wells with bacterial inoculum without ciprofloxacin, while negative control was done by preparing wells containing ciprofloxacin without bacterial inoculum. Results of the broth microdilution method were demonstrated according to the CLSI breakpoints for ciprofloxacin resistance (MIC $\geq 4 \mu \mathrm{g} / \mathrm{mL}$ ) [42]. Additionally, $\mathrm{MIC}_{50}$ and $\mathrm{MIC}_{90}$ of ciprofloxacin were identified as the lowest concentrations, which inhibit 50\% and $90 \%$ of the examined bacterial isolates, respectively [48]. 


\subsection{Conventional PCR and PCR-RFLP Assays}

Total DNA extraction was carried out using QIAamp DNA Mini Kit (Qiagen, Chatsworth, CA, USA) according to the manufacturer's instructions. Three pairs of oligonucleotide primers (Metabion, Bayern, Germany) targeting 23S rRNA, mapA and ceuE genes were used in conventional uniplex PCR assays for verification of the genera Campylobacter, C. jejuni and C. coli, respectively. Moreover, PCR-RFLP was used to determine FQ-resistant Campylobacter isolates by detecting the mutation in QRDR of gyrA gene using FastDigest $R s a$ I restriction enzyme (Thermo Fisher, Bremen, Germany) [15,17]. All PCR reactions were done in triplicate, using Emerald Amp GT PCR Master Mix (Takara, Kyoto, Japan). according to the manufacturer's instructions. Sequences of oligonucleotide primers used in all PCR assays are shown in Table $5[17,49,50]$. Agarose gel electrophoresis for visualization of PCR products were done as previously described [51]. Reference strains of $C$. jejuni (NCTC11322) and C. coli (NCTC11366) were used as positive controls, and PCR-grade water (no template DNA) was used as a negative control in PCR assays.

Table 5. Sequences of oligonucleotide primers targeting four genes of Campylobacter species and their PCR-amplified products.

\begin{tabular}{|c|c|c|c|}
\hline Specificity (Target Gene) & Primer Sequence $\left(5^{\prime}-3^{\prime}\right)$ & Amplified Product (bp) & Reference \\
\hline Genus Campylobacter (23S rRNA) & $\begin{array}{l}\text { F: TATACCGGTAAGGAGTGCTGGAG } \\
\text { R: ATCAATTAACCTTCGAGCACCG }\end{array}$ & 650 & [49] \\
\hline Campylobacter coli (ceuE) & $\begin{array}{l}\text { F: AATTGA AAATTG CTCCAACTATG } \\
\text { R: TGATTT TATTATTTGTAGCAGCG }\end{array}$ & 462 & {$[50]$} \\
\hline Campylobacter jejuni (mapA) & $\begin{array}{l}\text { F: CTATTTTATTTTTGAGTGCTTGTG } \\
\text { R: GCTTTATTTGCCATTTGTTTTATTA }\end{array}$ & 589 & {$[50]$} \\
\hline PCR-RFLP ( $g y r A)$ & $\begin{array}{c}\text { F: AAATCAGCCCTATAGTGGGTGCT- } \\
\text { GTTATAGGTCGTTAT C } \\
\text { ACCCACACATGGAGGT } \\
\text { R: TCAGTATAACGCATCGCAGC }\end{array}$ & 179 & [17] \\
\hline
\end{tabular}

\subsection{Statistical Analysis}

The data were analyzed using SPSS version 26 (IBM Corp, Armonk, NY, USA). The chi-square test was used to study the variations in the prevalence of Campylobacter spp. from different origins and to assess the differences in the antimicrobial resistance patterns of the recovered isolates from various sources and among $C$. jejuni and C. coli. The $p$ values were considered statistically significant if they were less than 0.05 .

\section{Conclusions}

This study revealed a high prevalence of MDR Campylobacter spp. in addition to the existence of both XDR and PDR strains among human and chicken isolates in Egypt. Therefore, there is an urgent need to control the antimicrobial usage in animal production and to improve the hygienic control strategies during slaughtering and carcass processing to reduce the occurrence of resistant Campylobacter strains. Interestingly, PCR-RFLP technique was found to be helpful in the detection of FQ-resistant Campylobacter isolates, which offer useful insights into the molecular mechanism involved in the FQ resistance in Campylobacter spp., which will help public health specialists in the management of Campylobacter infections. Furthermore, enhanced research efforts are required to illustrate the mechanisms of the transmission and persistence of FQ-resistant Campylobacter spp. alongside different hosts. Complementary to that, it is essential to provide a solid guideline for the administration of FQ antimicrobials especially in the veterinary field, which will decrease the wide spreading of human FQ-resistant Campylobacter isolates. A major limitation for our approach is the need for DNA sequencing to confirm the results of the mutation in QRDR of gyrA gene. 
Author Contributions: Conceptualization, A.M.A. and M.I.A.E.-H.; methodology, D.S.A., M.I.A.E.-H. and M.M.B.; software, R.M.S.E.-M.; validation, D.S.A., S.A. and M.M.A.-S.; formal analysis, M.I.A.E.-H., M.M.B., M.M.G. and W.E.S.; investigation, A.M.A., R.M.S.E.-M., M.M.G. and M.I.A.E.-H.; data curation, M.M.B. and M.I.A.E.-H.; writing—original draft preparation, A.M.A., M.I.A.E.-H., R.M.S.E.-M. and D.S.A.; writing - review and editing, M.I.A.E.-H. and M.M.B.; visualization, S.A.; supervision, A.M.A. and S.A.; project administration, M.M.A.-S., S.A. and M.M.G.; funding acquisition, M.M.A.-S., S.A. and M.M.G. All authors have read and agreed to the published version of the manuscript.

Funding: Mohammed M. Al-Sanea presents his gratitude to the deputyship for research and innovation; Ministry of Education in Saudi Arabia for supporting this work through the project number "37521350".

Institutional Review Board Statement: Not applicable.

Informed Consent Statement: The sole aim of the specimen collection in this study was to care for patients and to perform antimicrobial susceptibility testing for proper diagnosis and treatment. Therefore, it was not necessary to take ethical approval, but prior to starting the study, the participants provided informed consent.

Data Availability Statement: All data generated or analyzed during this study are included in the submitted manuscript.

Acknowledgments: Mohammed M. Al-Sanea presents his gratitude to the deputyship for research and in-novation; Ministry of Education in Saudi Arabia for supporting this work through the project number "375213500". Sarah Alboqmy gratefully acknowledges the support of Taif University Researchers Supporting project [number TURSP-2020/202], Taif University, Taif, Saudi Arabia.

Conflicts of Interest: The authors declare no conflict of interest.

\section{References}

1. Narvaez-Bravo, C.; Taboada, E.N.; Mutschall, S.K.; Aslam, M. Epidemiology of antimicrobial resistant Campylobacter spp. isolated from retail meats in Canada. Int. J. Food Microbiol. 2017, 253, 43-47. [CrossRef]

2. EFSA (European Food Safety Authority). Scientific opinion on quantification of the risk posed by broiler meat to human campylobacteriosis in the EU. EFSA J. 2010, 8, 1437. [CrossRef]

3. EFSA and ECDC (European Food Safety Authority and European Centre for Disease Prevention and Control). The European Union One Health 2019 Zoonoses Report. EFSA J. 2021, 19, e06406. [CrossRef]

4. Ammar, A.M.; El-Naenaeey, E.-S.Y.; El-Hamid, M.I.A.; El-Gedawy, A.A.; El-Malt, R.M.S. Campylobacter as a Major Foodborne Pathogen: A Review of Its Characteristics, Pathogenesis, Antimicrobial Resistance and Control. J. Microbiol. Biotechnol. Food Sci. 2021, 10, 609-619. [CrossRef]

5. Same, R.G.; Tamma, P.D. Campylobacter infections in children. Pediatr. Rev. 2018, 39, 533-541. [CrossRef]

6. Sibanda, N.; McKenna, A.; Richmond, A.; Ricke, S.C.; Callaway, T.; Stratakos, A.C.; Gundogdu, O.; Corcionivoschi, N. A review of the effect of management practices on campylobacter prevalence in poultry farms. Front. Microbiol. 2018, 9, 2002. [CrossRef] [PubMed]

7. Alaboudi, A.R.; Malkawi, I.M.; Osaili, T.M.; Abu-Basha, E.A.; Guitian, J. Prevalence, antibiotic resistance and genotypes of Campylobacter jejuni and Campylobacter coli isolated from chickens in Irbid governorate, Jordan. Int. J. Food Microbiol. 2020, 327, 108656. [CrossRef]

8. Ma, H.; Su, Y.; Ma, L.; Ma, L.; Li, P.; Du, X.; Gölz, G.; Wang, S.; Lu, X. Prevalence and characterization of Campylobacter jejuni isolated from retail chicken in Tianjin, China. J. Food Prot. 2017, 80, 1032-1040. [CrossRef]

9. Endtz, H.P. Campylobacter Infections. In Hunter's Tropical Medicine and Emerging Infectious Diseases; Elsevier: Amsterdam, The Netherlands, 2020; pp. 507-511.

10. Ammar, A.M.; El-Naenaeey, E.-S.Y.; El-Malt, R.M.S.; El-Gedawy, A.A.; Khalifa, E.; Elnahriry, S.S.; Abd El-Hamid, M.I. Prevalence, Antimicrobial Susceptibility, Virulence and Genotyping of Campylobacter jejuni with a Special Reference to the Anti-Virulence Potential of Eugenol and Beta-Resorcylic Acid on Some Multi-Drug Resistant Isolates in Egypt. Animals 2021, 1, 3. [CrossRef]

11. Luangtongkum, T.; Jeon, B.; Han, J.; Plummer, P.; Logue, C.M.; Zhang, Q. Antibiotic resistance in Campylobacter: Emergence, transmission and persistence. Future Microbiol. 2009, 4, 189-200. [CrossRef]

12. Abd El-Tawab, A.A.; Ammar, A.M.; Ahmed, H.A.; Hofy, F.I.E.; Hefny, A.A. Fluoroquinolone resistance and gyrA mutations in Campylobacter jejuni and Campylobacter coli isolated from chicken in Egypt. J. Glob. Antimicrob. Resist. 2018, 13, 22-23. [CrossRef]

13. Wieczorek, K.; Osek, J. Antimicrobial resistance mechanisms among campylobacter. Biomed. Res. Int. 2013, 2013, 340605. [CrossRef]

14. Said, M.M.; El-Mohamady, H.; El-Beih, F.M.; Rockabrand, D.M.; Ismail, T.F.; Monteville, M.R.; Ahmed, S.F.; Klena, J.D.; Salama, M.S. Detection of gyrA Mutation Among Clinical Isolates of Campylobacter jejuni Isolated in Egypt by MAMA-PCR. J. Infect. Dev. Ctries. 2010, 4, 546-554. [CrossRef] [PubMed] 
15. Sierra-Arguello, Y.M.; Furian, T.Q.; Perdoncini, G.; Moraes, H.L.S.; Salle, C.T.P.; Rodrigues, L.B.; dos Santos, L.R.; Gomes, M.J.P.; Nascimento, V.P.D. Fluoroquinolone resistance in Campylobacter jejuni and Campylobacter coli from poultry and human samples assessed by PCR-restriction fragment length polymorphism assay. PLoS ONE 2018, 13, e0199974. [CrossRef] [PubMed]

16. World Health Organization. WHO Publishes List of Bacteria for Which New Antibiotics Are Urgently Needed; WHO: Geneva, Switzerland, 2017.

17. Sierra-Arguello, Y.M.; Perdoncini, G.; Morgan, R.B.; Salle, C.T.P.; Moraes, H.L.S.; Gomes, M.J.P.; Nascimento, V.P.D. Fluoroquinolone and macrolide resistance in Campylobacter jejuni isolated from broiler slaughterhouses in southern Brazil. Avian Pathol. 2016, 45, 66-72. [CrossRef]

18. Ghaly, M.; Shaheen, A.; Bouhy, A.; Bendary, M. Alternative therapy to manage otitis media caused by multidrug-resistant fungi. Arch. Microbiol. 2020, 202,1-10. [CrossRef]

19. Bendary, M.M.; Solyman, S.M.; Azab, M.M.; Mahmoud, N.F.; Hanora, A.M. Genetic diversity of multidrug resistant Staphylococcus aureus isolated from clinical and non clinical samples in Egypt. Cell. Mol. Biol. 2016, 62, 55. [PubMed]

20. Abd El-Aziz, N.K.; Abd El-Hamid, M.I.; Bendary, M.M.; El-Azazy, A.A.; Ammar, A.M. Existence of vancomycin resistance among methicillin resistant S. aurues recovered from animal and human sources in Egypt. Slov. Vet. Res. 2018, 55, 221-230.

21. Ghaith, D.M.; Zafer, M.M.; Said, H.M.; Elanwary, S.; Elsaban, S.; Al-Agamy, M.H.; Bohol, M.F.F.; Bendary, M.M.; Al-Qahtani, A.; Al-Ahdal, M.N. Genetic diversity of carbapenem-resistant Klebsiella Pneumoniae causing neonatal sepsis in intensive care unit, Cairo, Egypt. Eur. J. Clin. Microbiol. Infect. Dis. 2019, 39, 583-591. [CrossRef] [PubMed]

22. Bendary, M.M.; Ibrahim, D.; Mosbah, R.A.; Mosallam, F.; Hegazy, W.A.H.; Awad, N.F.S.; Alshareef, W.A.; Alomar, S.Y.; Zaitone, S.A.; Abd El-Hamid, M.I. Thymol Nanoemulsion: A New Therapeutic Option for Extensively Drug Resistant Foodborne Pathogens. Antibiotics 2021, 10, 25. [CrossRef]

23. Ibrahim, D.; Abdelfattah-Hassan, A.; Badawi, M.; Ismail, T.A.; Bendary, M.M.; Abdelaziz, A.M.; Mosbah, R.A.; Mohamed, D.I.; Arisha, A.H.; El-Hamid, M.I.A. Thymol nanoemulsion promoted broiler chicken's growth, gastrointestinal barrier and bacterial community and conferred protection against Salmonella Typhimurium. Sci. Rep. 2021, 11, 7742. [CrossRef] [PubMed]

24. Ammar, A.M.; Attia, A.M.; Marwa, I.; Abd El-Hamid, M.I.; El-Shorbagy, I.M.; Shaimaa, A.; Abd El-Kader, S.A. Genetic basis of resistance waves among methicillin resistant Staphylococcus aureus isolates recovered from milk and meat products in Egypt. Cell. Mol. Biol. 2016, 62, 7-15. [PubMed]

25. Abd El-Hamid, M.I.; Bendary, M.M.; Merwad, A.M.A.; Elsohaby, I.; Ghaith, D.M.; Alshareef, W.A. What is behind phylogenetic analysis of hospital-, communityand livestock-associated methicillin-resistant Staphylococcus aureus? Transbound. Emerg. Dis. 2019, 66, 1506-1517. [PubMed]

26. Marwa, I. Abd El-Hamid; Bendary, M.M. Comparative phenotypic and genotypic discrimination of methicillin resistant and susceptible Staphylococcus aureus in Egypt. Cell. Mol. Biol. 2015, 61, 106-117.

27. Wieczorek, K.; Denis, E.; Osek, J. Comparative analysis of antimicrobial resistance and genetic diversity of Campylobacter from broilers slaughtered in Poland. Int. J. Food Microbiol. 2015, 210, 24-32. [CrossRef] [PubMed]

28. Mohammed, A.N.; Abdel Aziz, S.A.A. The prevalence of Campylobacter species in broiler flocks and their environment: Assessing the efficiency of chitosan/zinc oxide nanocomposite for adopting control strategy. Environ. Sci. Pollut. Res. 2019, 26, 30177-30187. [CrossRef]

29. Abd El-Hamid, M.I.; Abd El-Aziz, N.K.; Samir, M.; El-Naenaeey, E.; Sayed, Y.; Abo Remela, E.M.; Mosbah, R.A.; Bendary, M.M. Genetic Diversity of Campylobacter jejuni Isolated from Avian and Human Sources in Egypt. Front. Microbiol. 2019, 10, 2353. [CrossRef] [PubMed]

30. Abd El-Tawab, A.; El Hofy, F.; Ammar, A.; Ahmed, H.; Hefny, A. Bacteriological and Molecular Identification of Campylobacter Species in Chickens and Humans, at Zagazig City, Egypt. Benha Vet. Med. J. 2015, 28, 17-26. [CrossRef]

31. Abd El-Aziz, N.K.; Ammar, A.M.; Hamdy, M.M.; Gobouri, A.A.; Azab, E.; Sewid, A.H. First Report of aacC5-aadA7 44 Gene Cassette Array and Phage Tail Tape Measure Protein on Class 1 Integrons of Campylobacter Species Isolated from Animal and Human Sources in Egypt. Animals 2020, 10, 2067. [CrossRef]

32. Gharbi, M.; Béjaoui, A.; Ben Hamda, C.; Jouini, A.; Ghedira, K.; Zrelli, C.; Hamrouni, S.; Aouadhi, C.; Bessoussa, G.; Ghram, A.; et al. Prevalence and antibiotic resistance patterns of Campylobacter spp. isolated from broiler chickens in the North of Tunisia. Biomed. Res. Int. 2018, 2018. [CrossRef] [PubMed]

33. Wei, B.; Cha, S.Y.; Yoon, R.H.; Kang, M.; Roh, J.H.; Seo, H.S.; Lee, J.A.; Jang, H.K. Prevalence and antimicrobial resistance of Campylobacter spp. isolated from retail chicken and duck meat in South Korea. Food Control. 2016, 62, 63-68. [CrossRef]

34. Chatur, Y.A.; Brahmbhatt, M.N.; Modi, S.; Nayak, J.B. Fluoroquinolone resistance and detection of topoisomerase gene mutation in Campylobacter jejuni isolated from animal and human sources. Int. J. Curr. Microbiol. App. Sci. 2014, 3, 773-783.

35. Samad, A.; Abbas, F.; Ahmed, Z.; Akbar, A.; Naeem, M.; Sadiq, M.B.; Ali, I.; Bugti, F.S.; Achakzai, S.K. Prevalence, antimicrobial susceptibility, and virulence of Campylobacter jejuni isolated from chicken meat. J. Food Saf. 2019, 39, e12600. [CrossRef]

36. Igwaran, A.; Okoh, A.I. Occurrence, Virulence and Antimicrobial Resistance-Associated Markers in Campylobacter Species Isolated from Retail Fresh Milk and Water Samples in Two District Municipalities in the Eastern Cape Province, South Africa. Antibiotics 2020, 9, 426. [CrossRef]

37. Abd El-Hamid, M.I.; El-Naenaeey, E.Y.; Kandeel, T.M.; Hegazy, W.A.H.; Mosbah, R.A.; Nassar, M.S.; Bakhrebah, M.A.; Abdulaal, W.H.; Alhakamy, N.A.; Bendary, M.M. Promising Antibiofilm Agents: Recent Breakthrough against Biofilm Producing Methicillin-Resistant Staphylococcus aureus. Antibiotics 2020, 9, 667. [CrossRef] 
38. Abd El-Hamid, M.I.; El-Sayed, M.E.; Ali Aisha, R.; Abdallah, H.M.; Marwa, I.A.; El-mowalid, G.A. Marjoram extract downregulates the expression of Pasteurella multocida adhesion, colonization and toxin genes: A potential mechanism for its antimicrobial activity. Comp. Immunol. Microbiol. Infect. Dis. 2019, 62, 101-108. [CrossRef]

39. Hegazy, W.A.; Khayat, M.T.; Ibrahim, T.S.; Nassar, M.S.; Bakhrebah, M.A.; Abdulaal, W.H.; Alhakamy, N.A.; Bendary, M.M. Repurposing Anti-diabetic Drugs to Cripple Quorum Sensing in Pseudomonas aeruginosa. Microorganisms 2020, 8, 1285. [CrossRef]

40. ISO10272-1. Microbiology of Food and Animal Feeding Stuffs-Horizontal Method for the Detection and Enumeration of Campylobacter spp. Part. 1: Detection Method; ISO: Geneva, Switzerland, 2006.

41. Bauer, A.W.; Kirby, W.M.; Sherris, J.C.; Turck, M. Antibiotic susceptibility testing by a standardized single disk method. Am. J. Clin. Pathol. 1966, 45, 493-496. [CrossRef] [PubMed]

42. Clinical and Laboratory Standards Institute. Methods for Antimicrobial Dilution and Disk Susceptibility Testing of Infrequently Isolated or Fastidious Bacteria, 3rd ed.; CLSI Guideline M45; CLSI: Wayne, PA, USA, 2015.

43. Clinical and Laboratory Standards Institute. Performance Standards for Antimicrobial Susceptibility Testing, 27th ed.; CLSI Supplement M100; CLSI: Wayne, PA, USA, 2017.

44. Magiorakos, A.P.; Srinivasan, A.; Carey, R.B.; Carmeli, Y.; Falagas, M.E.; Giske, C.G.; Harbarth, S.; Hindler, J.F.; Kahlmeter, G.; Olsson-Liljequist, B.; et al. Multidrug-resistant, extensively drug-resistant and pandrug-resistant bacteria: An international expert proposal for interim standard definitions for acquired resistance. Clin. Microbiol. Infect. 2012, 18, 268-281. [CrossRef] [PubMed]

45. Sandhu, R.; Dahiya, S.; Sayal, P. Evaluation of multiple antibiotic resistance (MAR) index and Doxycycline susceptibility of Acinetobacter species among inpatients. Indian J. Microbiol. Res. 2016, 3, 299-304. [CrossRef]

46. Gahamanyi, N.; Song, D.-G.; Cha, K.H.; Yoon, K.-Y.; Mboera, L.E.G.; Matee, M.I.; Mutangana, D.; Amachawadi, R.G.; Komba, E.V.G.; Pan, C.-H. Susceptibility of Campylobacter Strains to Selected Natural Products and Frontline Antibiotics. Antibiotics 2020, 9, 790. [CrossRef]

47. Parvekar, P.; Palaskar, J.; Metgud, S.; Maria, R.; Dutta, S. The minimum inhibitory concentration (MIC) and minimum bactericidal concentration (MBC) of silver nanoparticles against Staphylococcus aureus. Biomater. Investig. Dent. 2020, 7, 105-109. [CrossRef]

48. Catania, S.; Bottinelli, M.; Fincato, A.; Gastaldelli, M.; Barberio, A.; Gobbo, F.; Vicenzoni, G. Evaluation of Minimum Inhibitory Concentrations for 154 Mycoplasma synoviae isolates from Italy collected during 2012-2017. PLoS ONE 2019, 14, e0224903. [CrossRef] [PubMed]

49. Wang, G.; Clark, C.G.; Taylor, T.M.; Pucknell, C.; Barton, C.; Price, L.; Woodward, D.L.; Rodgers, F.G. Colony multiplex PCR assay for identification and differentiation of Campylobacter jejuni, C. coli, C. lari, C. upsaliensis, and C. fetus subsp. fetus. J. Clin. Microbiol. 2002, 40, 4744-4747. [CrossRef] [PubMed]

50. Shin, E.; Lee, Y. Comparison of Three Different Methods for Campylobacter Isolation from Porcine Intestines. J. Microbiol. Biotechnol. 2009, 19, 647-650. [PubMed]

51. Sambrook, J.; Fritsch, E.F.; Maniatis, T. Molecular Cloning: A Laboratory Manual, 2nd ed.; Cold Spring Harbor Laboratory Press: New York, NY, USA, 1989. 